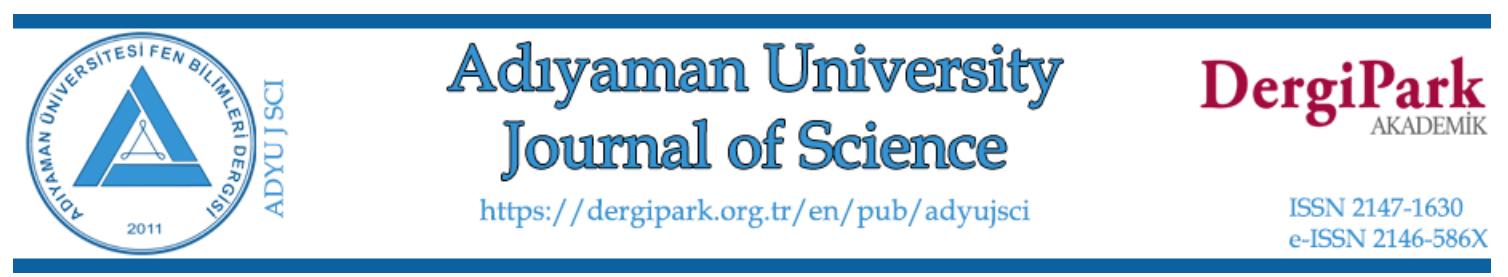

\title{
Annealing Effect on Magneto-impedance in CoSiB Wires
}

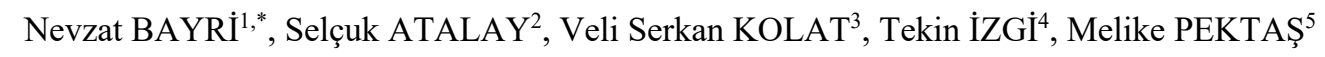

${ }^{1}$ Department of Mathematics and Science, Education Faculty, Inonu University, Malatya, Turkey, nevzat.bayri@inonu.edu.tr,ORCID:0000-0001-7105-7707

${ }^{2}$ Physics Department, Science and Arts Faculty, Inonu University, Malatya, Turkey, selcuk.atalay@inonu.edu.tr, ORCID:0000-0002-8840-7766

${ }^{3}$ Physics Department, Science and Arts Faculty, Inonu University, Malatya, Turkey, veli.kolat@inonu.edu.tr ORCID:0000-0002-8864-5051

${ }^{4}$ Physics Department, Science and Arts Faculty, Inonu University, Malatya, Turkey, tekin.izgi@inonu.edu.tr,ORCID:0000-0002-4489-905X

${ }^{5}$ Physics Department, Science and Arts Faculty, Inonu University, Malatya, Turkey, dr.melikepektas@gmail.com,ORCID:0000-0003-2119-5014

\section{Abstract}

In this study, thermal treatments dependence of Magneto-impedance (MI) effect in $\mathrm{Co}_{72.5} \mathrm{Si}_{12.5} \mathrm{~B}_{15}$ wires has been investigated. Wires were annealed at $460{ }^{\circ} \mathrm{C}$ for different times (1$400 \mathrm{~min}$ ). It was found that low time annealed leads to increase in magnetic softness. The largest change in the MI was observed at $1 \mathrm{MHz}$ frequency value. It was determined that maximum MI, coercivity $\left(\mathrm{H}_{\mathrm{c}}\right)$ and maximum field sensitivity $(\mathrm{S})$ values were $247 \%, 1.28 \mathrm{~A} / \mathrm{m}$ and $1.35 \%$ per $\mathrm{A} / \mathrm{m}$ respectively in the wire annealed at $460{ }^{\circ} \mathrm{C}$ for 10 minutes. This high MI and field sensitivity value occurring in low annealed time shows that this wire can be used in the design of low magnetic field sensors.

Keywords: Amorphous wire; Magneto-impedance; Coercivity.

\section{CoSiB Tellerin Manyeto-empedansında Isıl İşlem Etkisi}

$\ddot{O} \mathbf{z}$ 
$\mathrm{Bu}$ çalışmada $\mathrm{Co}_{72.5} \mathrm{Si}_{12.5} \mathrm{~B}_{15}$ tellerde Manyeto-empedans (ME) etkinin 1s1 işleme bağ $\operatorname{lil}_{1} \mathrm{ğ}_{1}$ incelenmiştir. Numuneler $460^{\circ} \mathrm{C}$ 'de farklı sürelerde 1sıtılmıştır (1-400 dakika). Düşük süreli 1sıl işlemlerin manyetik yumuşaklıkta artışa yol açtı̆̆ 1 bulunmuştur. MI değerinde en büyük değişim $1 \mathrm{MHz}$ frekans değerinde gözlenmiştir. MI, $\mathrm{H}_{\mathrm{c}}$ ve maksimum alan hassasiyet (S) değerleri 460 ${ }^{\circ} \mathrm{C}$ 'de 10 dakika 1 sıl işlemde sırasıyla $\% 247,1.28 \mathrm{~A} / \mathrm{m}$ ve A/m başına $\% 1.35$ olarak belirlenmiştir. Düşük 1sıl işlem süresinde ortaya çıkan bu yüksek MI ve alan hassasiyet değeri bu telin düşük manyetik alan sensörlerinin tasarımında kullanılabileceğini göstermektedir.

Anahtar Kelimeler: Amorf tel; Manyetoempedans; Koersivite.

\section{Introduction}

The magneto impedance (MI) effect in amorphous wire, strip and films has been interesting due to the possible technological applications of these materials. [1-12]. When a magnetic material carrying a low intensity, high frequency alternating current is subjected to an external magnetic field, it exhibits a sharp change in its electrical impedance. This effect is known as the magneto impedance (MI) effect [1, 2]. In sensitive magnetic field sensor designs, besides high MI variation, field sensitivity values have an important place. The field sensitivity value of the MI against the applied external magnetic field is calculated using equation 1 as follows [2].

$$
S=d\left(\frac{\Delta Z}{Z}\right) / d H
$$

Alloy composition is important in obtaining MI curves. Different domain structures are observed depending on the alloy composition [2]. The domain structure of a material obtained by rapid cooling is determined by the interaction between internal stresses and magnetostriction [2]. Accordingly, the sign and magnitude of the magnetostriction value has an important role in MI effect. Magnetostriction value in amorphous ferromagnetic wires is negative in Fe based wires, positive in Co-based wires and approximately zero in CoFe based wires [2, 13-15]. Depending on the sign and magnitude of the magnetostricrion value, MI curves show single or double peak behaviors.

Different annealing treatment, such as furnace and current has an important role in the exchange of MI data [16-20]. In $\mathrm{Co}_{75} \mathrm{Fe}_{4.2} \mathrm{Si}_{8} \mathrm{~B}_{12} \mathrm{Nb}_{0.8}$ wires, the change of MI effect with annealing was studied [21]. In this study, while the maximum MI value was observed at a temperature of $450{ }^{\circ} \mathrm{C}$ for 25 minutes, it was observed that the value of MI decreased due to the formation of nanocrystalline phases at annealed above 25 minutes. Annealing applied to amorphous materials causes changes in MI effect. Therefore, in this work the thermal treatments dependence of $\mathrm{MI}$ effect in $\mathrm{Co}_{72.5} \mathrm{Si}_{12.5} \mathrm{~B}_{15}$ wires was investigated. 


\section{Materials and Methods}

The $\mathrm{Co}_{72.5} \mathrm{Si}_{12.5} \mathrm{~B}_{15}$ wires produced by the melt spinning technique were cut $10 \mathrm{~cm}$ long. Samples were annealed in air in a non-inductive tube furnace at temperature of $460{ }^{\circ} \mathrm{C}$ for different times (1-400 min). The $\mathrm{M}-\mathrm{H}$ curves were obtained using a dc digital system; the coercivity $\left(\mathrm{H}_{\mathrm{c}}\right)$ was derived from the M-H curves. Sample impedance was measured using HP4294 impedance analyzer and HP4294A probe. MI data were obtained at $100 \mathrm{kHz}, 1 \mathrm{MHz}, 5$ $\mathrm{MHz}$ and $10 \mathrm{MHz}$ frequencies with $5 \mathrm{~mA}$ constant amplitude ac current. In magneto impedance measurements, solenoid was used for the outer dc magnetic field. The application of the Dc current along the solenoid was controlled by a computer. MI measurement system is given in Fig. 1. The data from the impedance analyzer were collected and averaged by the computer at each step of the magnetic field. The average of the impedance data leads to a large reduction in noise / signal ratio and thus clearer MI effect curves. The MI ratio was calculated from the equation $\Delta \mathrm{Z} / \mathrm{Z}(\%)=100[\mathrm{Z}(\mathrm{H})-\mathrm{Z}(\mathrm{Hmax})] / \mathrm{Z}(\mathrm{H} \max )$, where $\mathrm{Zmax}$ is the impedance measured at a magnetic field of $\mathrm{H} \approx 7400 \mathrm{~A} / \mathrm{m}$.

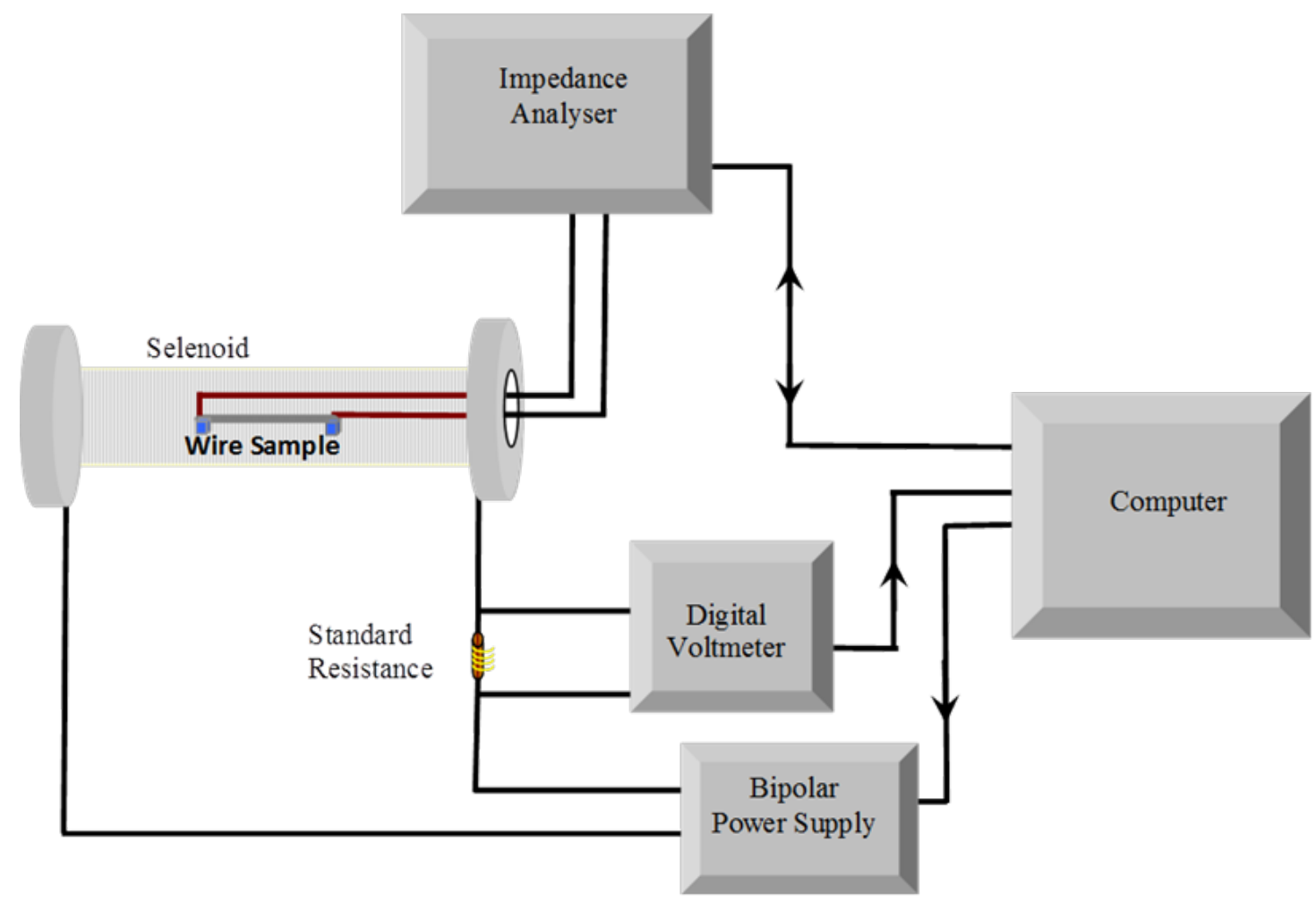

Figure 1: MI measurement system 


\section{Results}

Fig. 2 shows MI curves for the as-received $\mathrm{Co}_{72.5} \mathrm{Si}_{12.5} \mathrm{~B}_{15}$ wire at various frequencies. MI values for $100 \mathrm{kHz}, 1 \mathrm{MHz}, 5 \mathrm{MHz}$ and $10 \mathrm{MHz}$ frequency values were measured as $67 \%, 149 \%$, $81 \%$ and $68 \%$, respectively. Fig. 3 presents the dependence of impedance on magnetic field in asreceived and annealed samples in a particular case of $1 \mathrm{MHz}$. Since the as-received $\mathrm{CoSiB}$ wire has a negative magnetostriction value, double peak behaviors were observed in the curves. [2, $14]$.

MI curves of $\mathrm{Co}_{72.5} \mathrm{Si}_{12.5} \mathrm{~B}_{15}$ wires, which are as-received and annealed at different times, was shown in Fig. 4. These curves were obtained by applying the frequency of $1 \mathrm{MHz}$. The highest value in magneto-impedance measurements was obtained on the wire which was annealed at 460 ${ }^{\circ} \mathrm{C}$ for 10 minutes. MI value for this wire was found to be $247 \%$. It was determined that MI values changed with increasing annealed time and after 400 minutes the value decreased to $113 \%$.

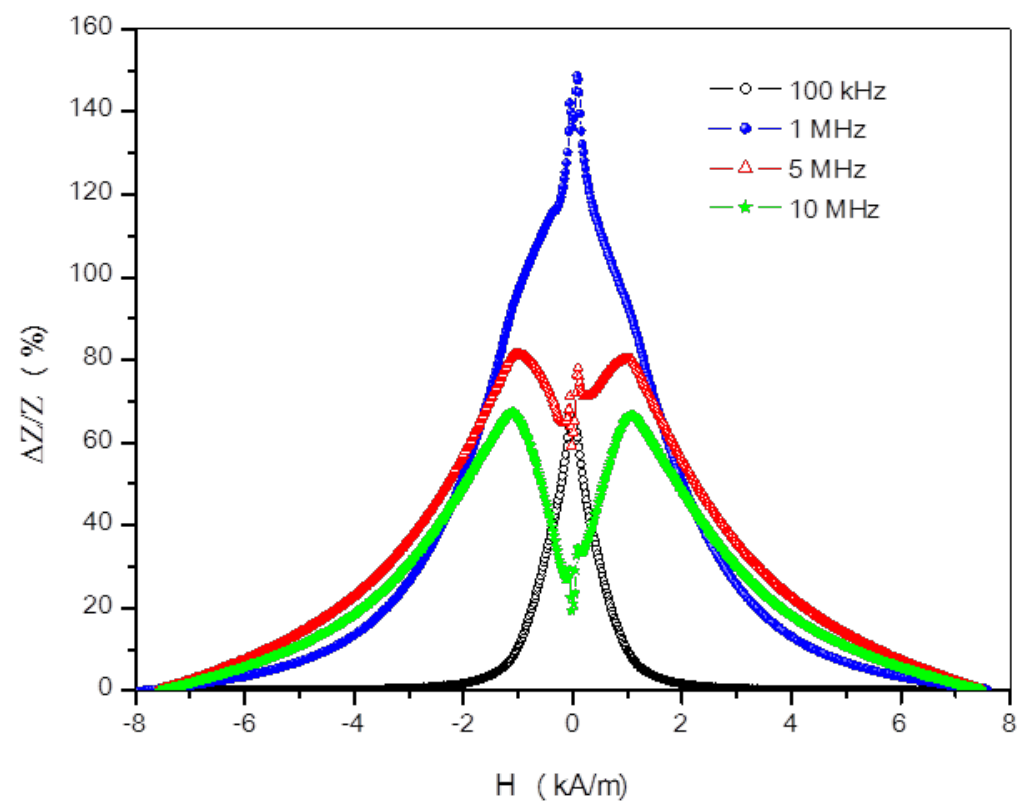

Figure 2: MI curves of as-received $\mathrm{C}_{72.5} \mathrm{Si}_{12.5} \mathrm{~B}_{15}$ wire for different frequency 


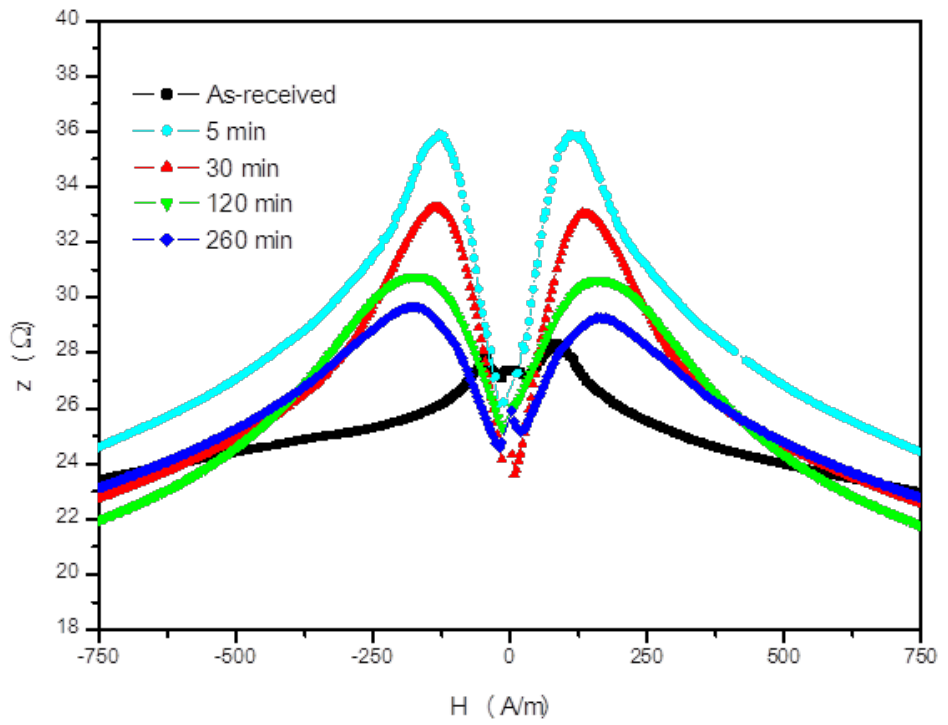

Figure 3: Impedance curves for as-received and annealed samples at $1 \mathrm{MHz}$

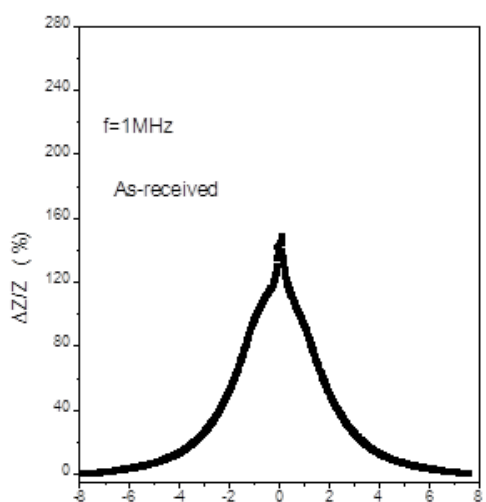

$\mathrm{H}(\mathrm{kA} / \mathrm{m})$

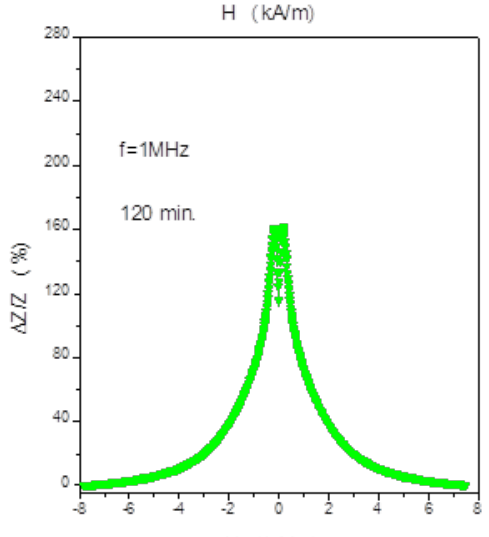

$\mathrm{H}(\mathrm{kA} / \mathrm{m})$

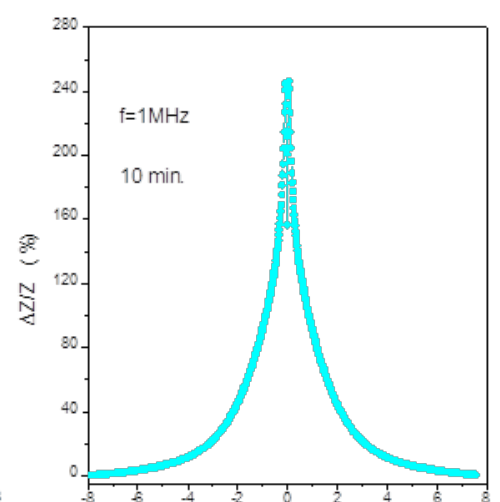

$\mathrm{H}(\mathrm{kA} / \mathrm{m})$

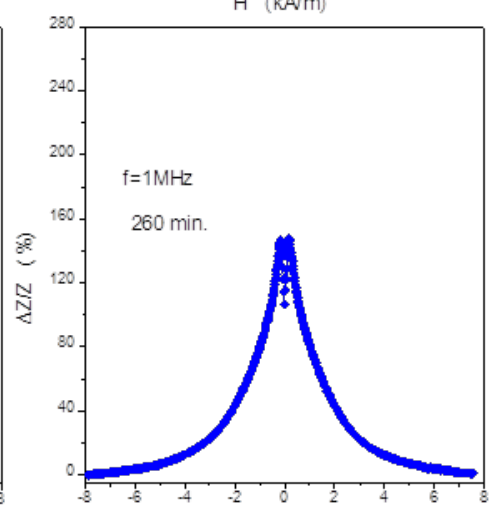

$\mathrm{H}(\mathrm{kA} / \mathrm{m})$

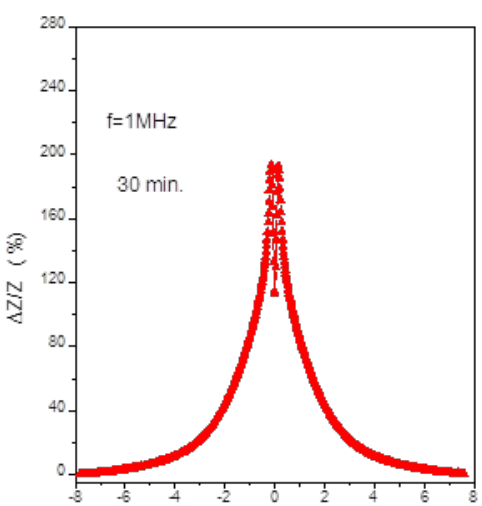

$\mathrm{H}(\mathrm{kA} / \mathrm{m})$

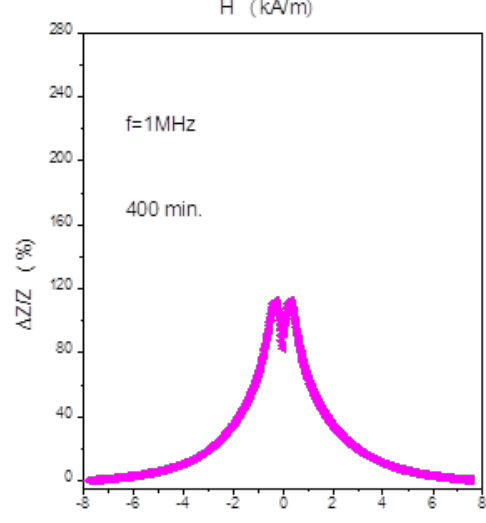

$\mathrm{H}(\mathrm{kA} / \mathrm{m})$

Figure 4: MI curves for as-received and annealed samples at $1 \mathrm{MHz}$ 
Fig. 5 shows variation of MI values as a function of annealing time for $\mathrm{Co}_{72.5} \mathrm{Si}_{12.5} \mathrm{~B}_{15}$ wires. The curves in Fig. 5 were obtained at the frequency values of $100 \mathrm{kHz}, 1 \mathrm{MHz}, 5 \mathrm{MHz}$ and $10 \mathrm{MHz}$.

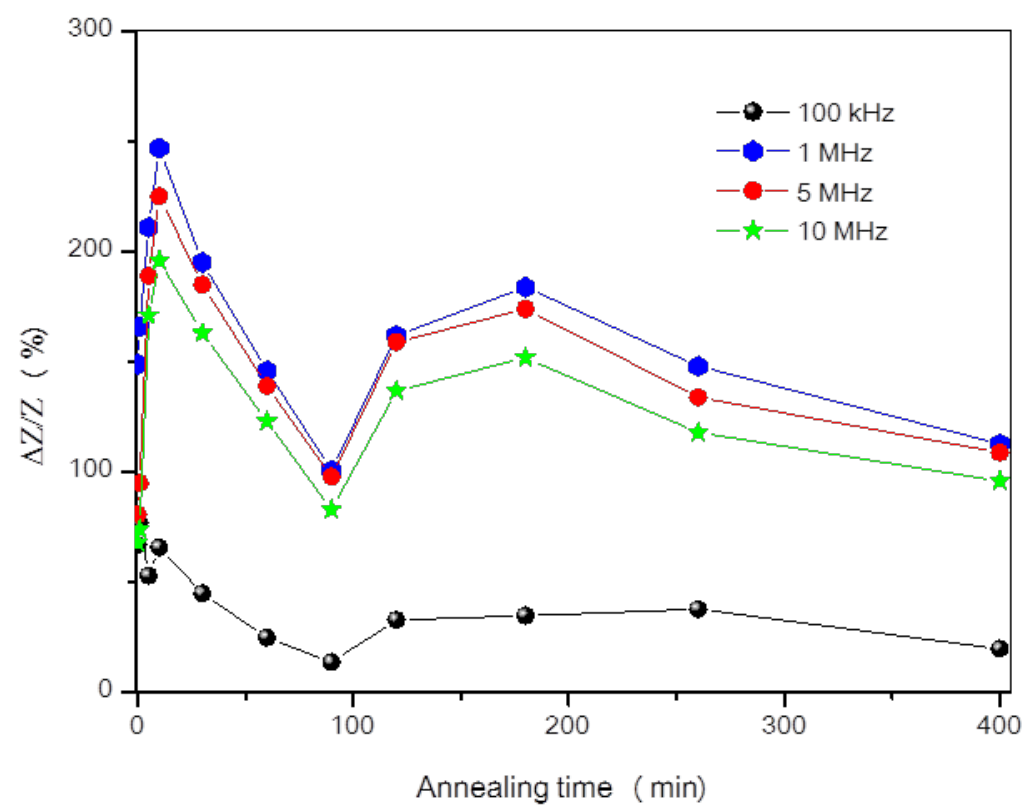

Figure 5: Variation of MI values as a function of annealing time

In the magnetic impedance measurements obtained for all frequency values, the greatest value has been observed on the wire annealed for 10 minutes. MI values were measured as $66 \%$, $247 \%, 225 \%$ and $196 \%$ for the frequency values of $100 \mathrm{kHz}, 1 \mathrm{MHz}, 5 \mathrm{MHz}$, and $10 \mathrm{MHz}$ respectively. As can be seen from Fig. 5, it is seen that MI values decrease sharply for all frequency values between 10-90 minutes. It was determined that MI values increased up to 180 minutes and decreased during the heat treatments over this time. MI values of $\mathrm{Co}_{72.5} \mathrm{Si}_{12.5} \mathrm{~B}_{15}$ wire annealed for 400 minutes. MI values were calculated as $20 \%, 113 \%, 109 \%$, and $96 \%$ for $100 \mathrm{kHz}$, $1 \mathrm{MHz}, 5 \mathrm{MHz}$, and $10 \mathrm{MHz}$ frequency values respectively at 400 minutes annealing time.

Fig. 6 shows the magnitude of the $\mathrm{MI}$ and $\mathrm{H}_{\mathrm{c}}$ values, a function of annealing time for the wires annealed at $460{ }^{\circ} \mathrm{C} . \mathrm{H}_{\mathrm{c}}$ and magneto-impedance changes were found to be compatible depending on the annealing time. 


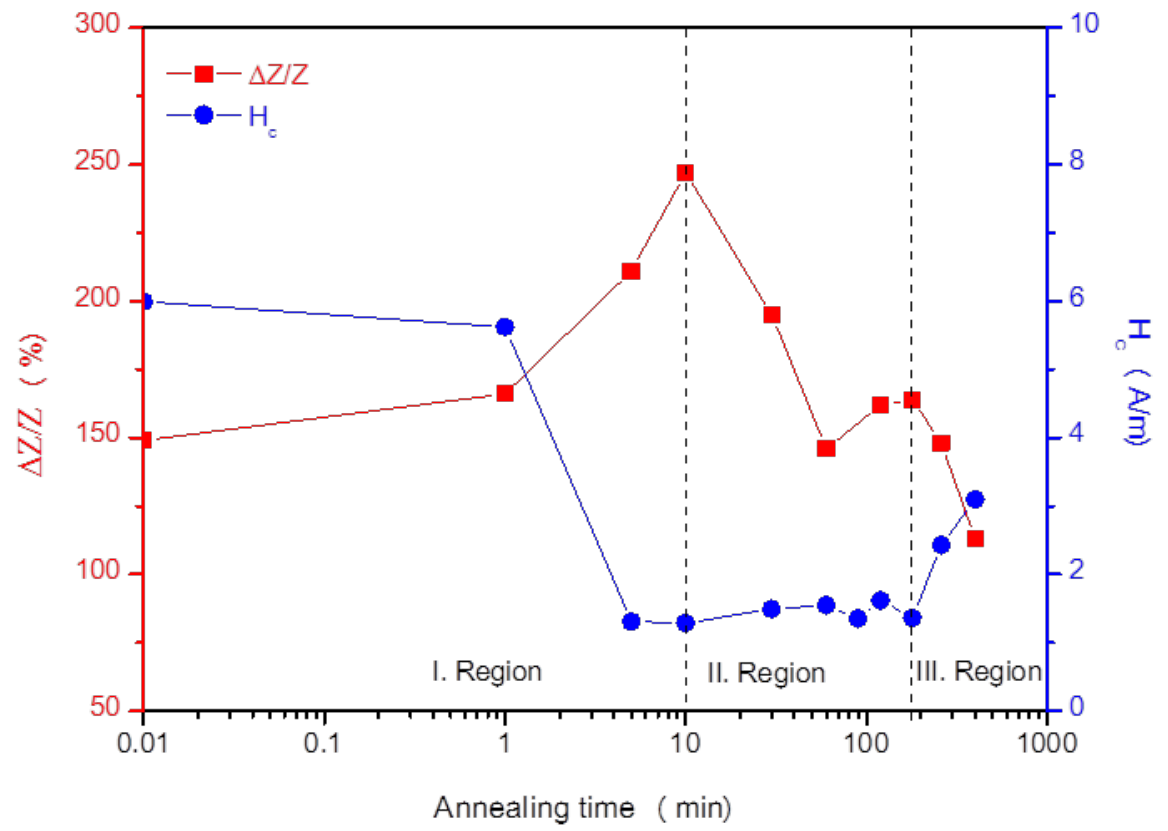

Figure 6: Variation of $\mathrm{MI}$ and $\mathrm{H}_{\mathrm{c}}$ values with annealing time

Impedance and field sensitivity values $(\mathrm{S})$ at $\pm 1000 \mathrm{~A} / \mathrm{m}$ external magnetic field value were plotted in Fig. 7. In Fig. 7 (a), the double peak behavior against the applied external magnetic field is clearly seen. $\mathrm{S}$ values were determined as $1.2 \%$ per $\mathrm{A} / \mathrm{m}$ and $1.35 \%$ per $\mathrm{A} / \mathrm{m}$ in the positive and negative magnetic field directions, respectively (Fig. 7 (b)).
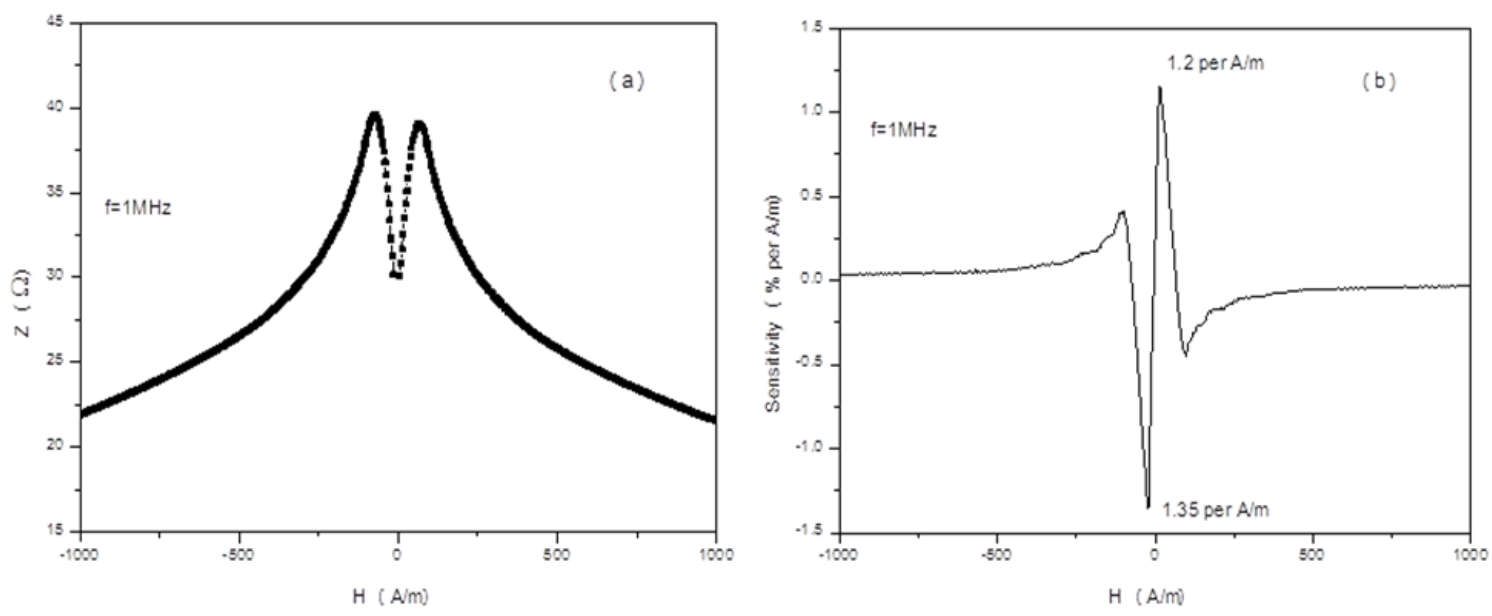

Figure 7: (a) Impedance, (b) field sensitivity values against the applied low field of the wire annealed at $460 \mathrm{C}$ for 10 minutes. (f=1 MHz)

\section{Discussion}

The magnetic permeability of the samples has an important role in the interpretation of MI data. The permeability of materials can be related to the skin effect. For a conductor carrying 
a sinusoidal alternating current, the penetration or skin depth, $d$, is given by the well-known expression $[22,23]$

$$
\delta=\left(\frac{2}{\omega \sigma \mu}\right)^{1 / 2} \text { and } Z \propto 1 / \delta
$$

where $\sigma$ is the conductivity, $\omega$ is the ac current frequency and $\mu$ is the permeability.

It is also well-known that the permeability of a magnetic material is proportional to the total anisotropy $(\mathrm{K})$ of a sample. For amorphous and nanocrystalline materials the main contributions to the anisotropy are the magneto-elastic anisotropy $\left(\mathrm{K}_{\mathrm{me}}\right)$, shape anisotropy $\left(\mathrm{K}_{\mathrm{D}}\right)$ and the magneto-crystalline anisotropy $\left(\mathrm{K}_{\text {mcrys }}\right)$ [4]. The $\mathrm{K}_{\mathrm{D}}$ contribution is similar in all samples since the lengths of the as-received and annealed samples are the same. For this reason, $\mathrm{K}_{\mathrm{me}}$ and $\mathrm{K}_{\text {mcrys }}$ are considered in the interpretation of the data. The total anisotropy value of the sample is inversely proportional to the impedance value due to magnetic permeability. Bearing this in mind, the effect of the annealing time on $(\Delta \mathrm{Z} / \mathrm{Z})(\%)$ and $\mathrm{H}_{\mathrm{c}}$ values can be divided into three regions (see Fig. 6).

As can be seen in Fig. 6, I. Region is low annealed time (up to 10 minutes), II. Region medium annealed time (30-180 minutes) and III. Region shows the annealed time over 180 minutes. In the low annealed time, it was determined that both the $\mathrm{H}_{\mathrm{c}}$ value reached a minimum $(1.28 \mathrm{~A} / \mathrm{m})$ and the magneto impedance value reached a maximum value $(247 \%)$. Annealing up to 10 min relieves the internal stresses, thus reducing $\mathrm{K}_{\mathrm{me}}$, and hence increasing MI values.

In the II. Region, a very small increase in $\mathrm{H}_{\mathrm{c}}$ values and a sharp decrease in magnetoimpedance value were observed up to 120 minutes of heat treatment. Between 120-180 minutes, a partial increase in magneto impedance value and very small changes in $\mathrm{H}_{c}$ values were determined. This is related to the surface crystallization that occurs in the sample $[4,16]$. In longer annealed time, in the III. Region (over 180 minutes), boron phases are formed in the building [21]. Due to the formation of these phases, magneto crystal anisotropy occurs in the amorphous structure and this leads to an increase in the total anisotropy in the sample. Therefore, it was determined that $\mathrm{H}_{\mathrm{c}}$ values increased and MI values decreased due to the increase of total anisotropy.

Field sensitivity values are also important in magnetic field sensor designs of samples with high MI variation. In the literature, the field sensitivity value for the as-received $\mathrm{Co}_{72.5} \mathrm{Si}_{12.5} \mathrm{~B}_{15}$ wire was calculated as $0.22 \%$ per $\mathrm{A} / \mathrm{m}$ [14]. In our study, $\mathrm{S}$ value was determined as approximately $1.35 \%$ per $\mathrm{A} / \mathrm{m}$ in the negative magnetic field region as a result of the low-time annealed (Fig. 7 (b)). This shows that the soft properties resulting from the low-time annealed increase the $S$ value. 


\section{Conclusion}

In this study, we observed that annealing time had a great effect on MI curves of $\mathrm{Co}_{72.5} \mathrm{Si}_{12.5} \mathrm{~B}_{15}$ wire. Especially low annealed time has been found to lead to an improvement in the magnetic softness, leading to an increase in MI effect. It was determined that $\mathrm{MI}$ and $\mathrm{H}_{\mathrm{c}}$ values were $247 \%$ and $1.28 \mathrm{~A} / \mathrm{m}$ in the wire annealed at $460{ }^{\circ} \mathrm{C}$ for 10 minutes. In addition, the $\mathrm{S}$ value of the wire annealed during this low-time was calculated as $1.35 \%$ in the negative magnetic field direction and $1.2 \%$ in the positive magnetic field direction per $\mathrm{A} / \mathrm{m}$. Maximum MI and $\mathrm{S}$ values indicate that this wire is suitable for magnetic field sensor design. When annealed time was over $180 \mathrm{~min}$, nanocrystalline phase growing up improves the magneto crystalline anisotropy and reduces the MI effect.

\section{References}

[1] Lenz, J., Edelstein, S., Magnetic sensors and their applications, IEEE Sensors Journal, 6(3), 631-64, 2006.

[2] Phan, M.H., Peng, H.X., Giant magnetoimpedance materials: Fundamentals and applications, Progress in Materials Science, 53(2), 323-420, 2008.

[3] Kurlyandskaya, G.V., Sanchez, M.L., Hernando, B., Prida, V.M., Gorria, P., Tejedor, M., Giant-magnetoimpedance-based sensitive element as a model for biosensors, Applied Physics Letters, 82(18), 3053-3055, 2003.

[4] Kolat, V.S., Bayri, N., Michalik, S., Izgi, T., Atalay, F.E., Gencer, H., Atalay, S., Magnetic and magnetoimpedance properties of Mn-doped FINEMET, Journal of NonCrystalline Solids, 355, 2562-2566, 2009.

[5] Vazquez, M., Knobel, M., Sanchez, M.L., Valenzuela, R., Zhukov, A.P., Giant magnetoimpedance effect in soft magnetic wires for sensor applications, Sensors and Actuators A-Physical, 59(1-3), 20-29, 1997.

[6] Velazquez, J., Vazquez, M., Chen, D.X., Hernando, A., Giant Magnetoimpedance in Nonmagnetostrictive Amorphous Wires, Physical Review B, 50(22), 16737-16740, 1994.

[7] Zhukov, A., Design of the magnetic properties of Fe-rich, glass-coated microwires for technical applications, Advanced Functional Materials, 16(5), 675-680, 2006.

[8] Atalay, F.E., Atalay, S., Giant magnetoimpedance effect in NiFe/Cu plated wire with various plating thicknesses, Journal of Alloys and Compounds, 392 (1-2), 322-328, 2005.

[9] Gazda, P., Szewczyk, R., Novel giant magnetoimpedance magnetic field sensor, Sensors, 20(3), 691, 2020.

[10] Xiao, S.Q., Liu, Y.H., Yan, S.S., Dai, Y.Y., Zhang, L., Mei, L.M., Giant magnetoimpedance and domain structure in $\mathrm{FeCuNbSiB}$ films and sandwiched films, Physical Review B, 61(8), 5734-5739, 2000.

[11] Phan, M.H., Peng, H.X., Wisnom, M.R., Yu, S.C., Giant magnetoimpedance effect in ultrasoft FeAlSiBCuNb nanocomposites for sensor applications, Journal of Applied Physics, 98(1), 014316, 2005. 
[12] Hernando, B., Sanchez, M.L., Prida, V.M., Tejedor, M., Vazquez, M., Magnetoimpedance effect in amorphous effect in amorphous and nanocrystalline ribbons, Journal of Applied Physics, 90(9), 4783-4790, 2001.

[13] Kamruzzaman, M., Rahman, I.Z., Rahman, M.A., A review on magneto-impedance effect in amorphous magnetic materials, Journal of Materials Processing Technology, 119(1-3), 312-317, 2001.

[14] Pal, S.K., Panda, A.K., Vazquez, M., Mitra, A., The effect of magnetoeleastic interaction on the GMI behaviour of $\mathrm{Fe}$-, $\mathrm{Co}$ - and Co-Fe-based amorphous wires, Journal of Materials Processing Technology, 172, 182-187, 2006.

[15] Zhukov, A., Ipatov, A., Talaat, A., Blanco, J.M., Zhukova, V., Engineering of Magnetic Properties of, Co-and Fe-rich Microwires, IEEE Transactions on Magnetics, 54(6), 2000707, 2018.

[16] Bayri, N., Kolat, V.S., Atalay, F.E., Atalay, S., The effect of furnace annealing and surface crystallization on the anisotropy, $\Delta E$ and magnetoimpedance effects in $\mathrm{Fe}_{71} \mathrm{Cr}_{7} \mathrm{Si}_{9} \mathrm{~B}_{13}$ amorphous wires, Journal of Physics D: Applied Physics, 37, 3067-3072, 2004.

[17] Atalay, S., Comparative study of magnetoimpedance effect in current and field annealed (Co0.9Fe0.05Ni0.05)(75)Si15B10 amorphous ribbons, Physica B-Condensed Matter, 368(1-4), 273-278, 2005.

[18] Dzhumazoda, A., Panina, L.V., Nematov, M.G., Yudanov, N.A., Tabarov, F.S., Morchenko, A.T., Ukhasov, A.A., Influence of Current Annealing on the Temperature Dependences of Magnetoimpedance in Amorphous Microwires, Technical Physics, 64(7), 990993, 2019.

[19] Celegato, F., Coisson, M., Olivetti, E., Tiberto, P., Vinai, F., A study of magnetic properties in CoFeSiB amorphous thin films submitted to furnace annealing, Physica Status Solidi A-Applications and Materials Science, 205(8), 1745-1748, 2008.

[20] Ghanaatshoar, M., Tehranchi, M.M., Mohseni, S.M., Roozmeh, S.E., Gharehbagh, A.J., Effect of magnetic field-current annealing on the magnetoimpedance of Co-based ribbons, Journal of Non-crystalline Solids, 353(8-10), 899-901, 2007.

[21] Shuling, Z., Dawei, X., Jianfei S., Effect of annealing on the giant magneto-impedance of Co-based Wires, International Journal of Modern Physics B, 23(6-7), 1265-1269, 2009.

[22] Machado, F.L.A., Rezende, S.M., A theoretical model for the giant magnetoimpedance in ribbons of amorphous soft-ferromagnetic alloys, Journal of Applied Physics, 79(8), 6558-6560, 1996.

[23] Panina, L.V., Mohri, K., Magneto-impedance effect in amorphous wires, Applied Physics Letter, 65, 1189-1191, 1994. 